\title{
Remote Sensing Estimates of Grassland Aboveground Biomass Based on MODIS Net Primary Productivity (NPP): A Case Study in the Xilingol Grassland of Northern China
}

\author{
Fen Zhao ${ }^{1}$, Bin Xu ${ }^{1}{ }^{*}$, Xiuchun Yang ${ }^{1}$, Yunxiang Jin ${ }^{1}$, Jinya $\mathrm{Li}^{1}$, Lang Xia ${ }^{1}$, Shi Chen ${ }^{2}$ \\ and Hailong $\mathrm{Ma}^{1}$
}

1 Key Laboratory of Agri-Informatics of Ministry of Agriculture, Institute of Agricultural Resources and Regional Planning, China Academy of Agriculture Sciences, Beijing 100081, China;

E-Mails: zhaofen198931@163.com (F.Z.); yangxiuchun@ caas.cn (X.Y.);

jinyunxiang@caas.cn (Y.J.); lijinya_rs@ hotmail.com (J.L.); xialang2012@163.com (L.X.); mahailong@ caas.cn (H.M.)

2 College of Territorial Resources and Tourism, An Hui Normal University, Wuhu 241000, China;

E-Mail: shic11@126.com

* Author to whom correspondence should be addressed; E-Mail: xubin@ caas.cn;

Tel./Fax: +86-10-8210-6232.

Received: 15 April 2014; in revised form: 28 May 2014 / Accepted: 3 June 2014 /

Published: 10 June 2014

\begin{abstract}
The precise and rapid estimation of grassland biomass is an important scientific issue in grassland ecosystem research. In this study, based on a field survey of 1205 sites together with biomass data of the Xilingol grassland for the years 2005-2012 and the "accumulated" MODIS productivity starting from the beginning of growing season, we built regression models to estimate the aboveground biomass of the Xilingol grassland during the growing season, then further analyzed the overall condition of the grassland and the spatial and temporal distribution of the aboveground biomass. The results are summarized as follows: (1) The unitary linear model based on the field survey data and "accumulated" MODIS productivity data is the optimum model for estimating the aboveground biomass of the Xilingol grassland during the growing period, with the model accuracy reaching 69\%; (2) The average aboveground biomass in the Xilingol grassland for the years 2005-2012 was estimated to be $14.35 \mathrm{Tg}$, and the average aboveground biomass density was estimated to be $71.32 \mathrm{~g} \cdot \mathrm{m}^{-2}$; (3) The overall variation in the aboveground biomass showed a decreasing trend from the eastern meadow grassland to the western
\end{abstract}


desert grassland; (4) There were obvious fluctuations in the aboveground biomass of the Xilingol grassland for the years 2005-2012, ranging from 10.56-17.54 Tg. Additionally, several differences in the interannual changes in aboveground biomass were observed among the various types of grassland. Large variations occurred in the temperate meadow-steppe and the typical grassland; whereas there was little change in the temperate desert-steppe and temperate steppe-desert.

Keywords: Xilingol; grassland; remote sensing; MOD17A2; aboveground biomass

\section{Introduction}

Grassland ecosystems are one of the most important types of terrestrial ecosystems on the planet. They provide the ecosystem functions of soil and water conservation, wind erosion prevention, sand fixation and air purification. They also play an important role in the global terrestrial circulation among ecosystems. In addition, grassland ecosystems are important for "livestock production". China's grasslands encompass an area of approximately 400 million hectares, accounting for $41.7 \%$ of the country's total land area [1], and constituting the single largest type of terrestrial ecosystem in China. Grassland biomass is the most direct indicator of grassland's ecological status [2]. Thus, a precise and rapid method for the estimation of grassland biomass is of great importance for both basic science and the management and protection of grasslands.

Grassland biomass directly reflects the level of grassland productivity. Productivity refers to the amount of organic matter produced by autotrophic organisms in a given unit of area over a given unit of time. Grassland net primary productivity (NPP) is obtained by subtracting autotrophic respiration [3] from the total amount of organic matter fixed by grassland vegetation. Grassland biomass is defined as the yield of fresh grass or hay that can be harvested at a certain time, and is close to the net primary productivity without regard to disturbances. Productivity is the basis for the formation of biomass, and biomass is the manifestation of productivity. The currently available methods for the estimation of grassland productivity and biomass primarily include field surveys, statistical modeling [4-7], process modeling [8-11] and parameter modeling [12-16].

With the development of remote sensing technology, more and more fields have begun to involve remote sensing technology $[17,18]$, and the development of remote sensing technology has stimulated studies on vegetation productivity and biomass. Due to the simple calculations involved and the high accuracy of the approach, statistical regression models using remote sensing data have been widely applied for the estimation of grassland biomass. The essence of the method is the establishment of a regression model between biomass measurements and either single-band remote sensing or vegetation index data, using satellite remote sensing data as the input parameters to estimate biomass. Initially, as the use of single-band information was simple, data of this type were used for estimating grassland biomass. However, due to strong interference from a number of factors (e.g., air, soil, sensor performance and the angle of the sun), the resulting estimation accuracy was found to be poor [19]. As such, the vegetation index is now commonly used as the form of input data for building empirical regression models of vegetation biomass. Piao, et al. [20] used the normalized difference vegetation 
index (NDVI) calculated by NOAA/AVHRR to establish a grassland vegetation biomass estimation model for China, and used the model to study the spatial distribution characteristics of China's grassland vegetation biomass. Advances in remote sensing technology have generated higher-resolution images that are now used to estimate grassland productivity and biomass through methods, such as the application of MODIS data. Xu, et al. [21] performed a systematic estimation of China's grassland productivity by region using a combination of MODIS data and ground survey data for the same time period. For different types of grassland areas, they established relational models between NDVI and field survey biomass data that allowed them to estimate the distribution of grass production in China. Yang, et al. [22] employed enhanced vegetation index (EVI) data from MODIS to estimate aboveground biomass in Tibet and analyze the relationship between the grassland's aboveground biomass and climatic factors. Gao, et al. [23] used the MODIS vegetation index to conduct in-depth research on the spatial distribution of the aboveground and underground biomass of the Xilingol grassland.

Using a remote sensing vegetation index to estimate aboveground biomass provides accurate and rapid results, but the limitations of the vegetation index itself may affect the obtained grassland biomass estimates. Specifically, in low-coverage grasslands, due to the significant influence of the soil background and grassland vegetation types, the estimation results exhibit high error rates. In addition, in high-coverage grasslands, the NDVI shows decreased sensitivity. A "saturation" phenomenon appears when the NDVI is higher, resulting in a decline in the accuracy of grassland biomass estimates. The MODIS productivity products regularly published by NASA are surface photosynthetic products obtained from model estimates. After processing these products, we established a relational model between the MODIS productivity products and field-measured aboveground biomass. We then estimated aboveground biomass by accepting the MODIS productivity data as input parameters to avoid or reduce saturation problems if the input parameters were too high. In the present study, based on this strategy, we used ground survey data from the Xilingol grassland for the years 2005-2012 and MODIS productivity data for the same time period to establish statistics-based models for estimating biomass. We further tested the accuracy of the models and selected the optimal model for estimating the aboveground biomass of the Xilingol grassland during the growing period.

\section{Materials and Methods}

\subsection{Overview of the Study Area}

The Xilingol grassland, located in the central part of Inner Mongolia at $41^{\circ} 35^{\prime} \sim 46^{\circ} 46^{\prime} \mathrm{N}$, $111^{\circ} 09^{\prime} \sim 119^{\circ} 58^{\prime} \mathrm{E}$ (Figure 1), is a typical temperate grassland of northern China, with an arid and semiarid temperate continental monsoon climate. The total area of the Xilingol grassland is $192,512 \mathrm{~km}^{2}$, accounting for $95.03 \%$ of the total land area of Xilingol. The map of grassland resources in China at a 1:1,000,000 scale shows that the vegetation types in the grassland, ranging from east to west, are meadow grassland, typical grassland and desert grassland (Figure 1). The representative plants of the meadow grassland are Leymus chinensis and Stipa baicalensis, whereas those of the typical grassland are bunch grasses such as Leymus chinensis, Stipa grandis and Stipa krylovii, and those of the desert grassland are dwarf grasses such as Stipa klemenzii, Stipa glareosa and Cleistogenes squarrosula [24]. 
Figure 1. Grassland types and the distribution of sampling sites in the study area. The total number of sampling sites was 1205 .

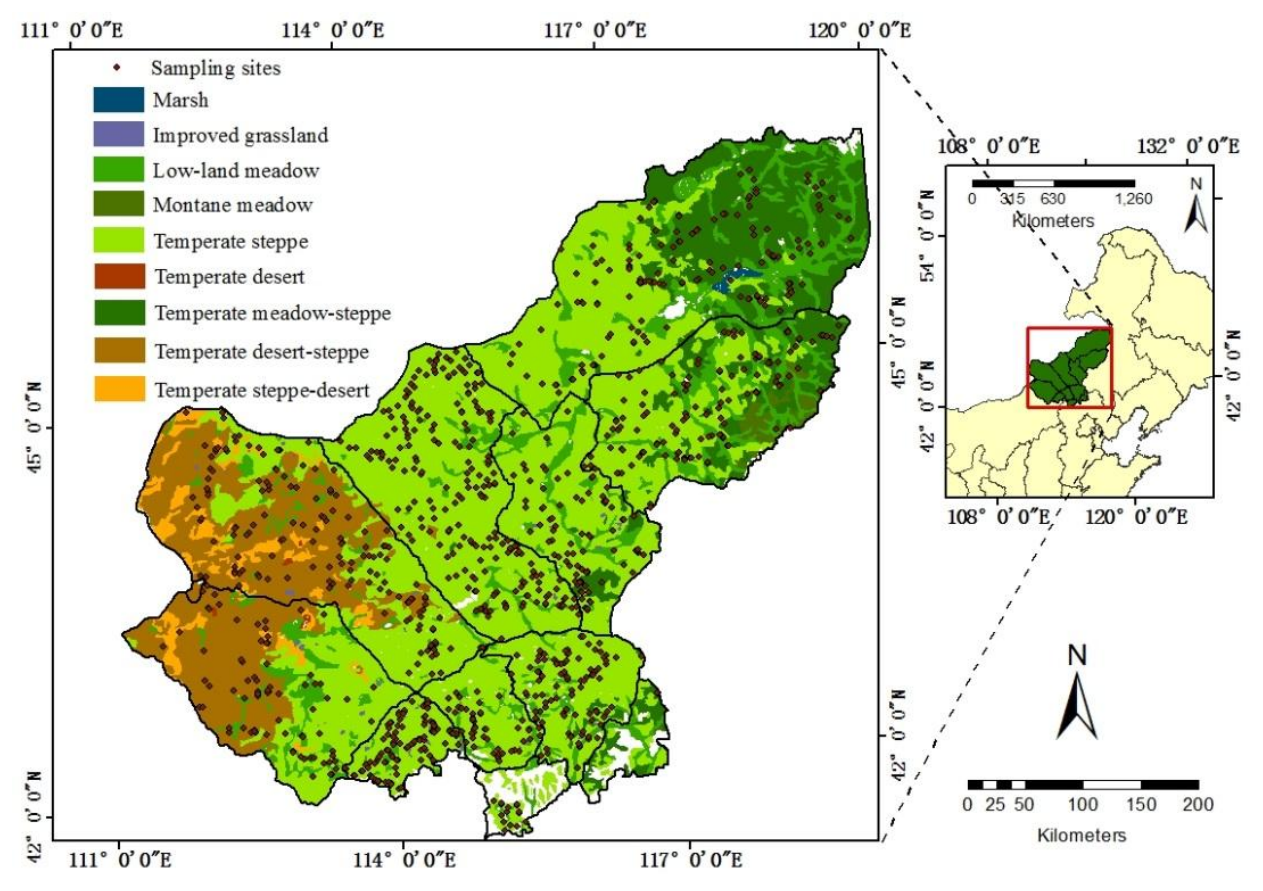

\subsection{Field Sampling Data}

The aboveground biomass data used in this study came from multi-year field survey data collected by our research group, and a large-scale field campaign organized by the Grassland Monitoring and Supervision Center Ministry of Agriculture of China (GMSC), primarily in July and August from 2005-2012 [23]. The sampling sites, each of which had an area of at least $1 \mathrm{~km}^{2}$, were chosen to represent typical vegetation communities. Each sampling site was homogeneous in terms of both its vegetation and land types. To obtain the actual aboveground biomass of herbs, all the aboveground plants in the three plots $(1 \mathrm{~m} \times 1 \mathrm{~m})$ were harvested to measure their fresh weight. To obtain the estimated aboveground biomass of shrubs in the homogeneous grassland, one plot $(10 \mathrm{~m} \times 10 \mathrm{~m})$ was sampled. We sorted the shrub plants (clumps) into three groups by size (i.e., large, medium and small). A representative plant (clump) from each group was selected, and its green parts along with its branches were cut and weighed from the same year. For each shrub plot, we multiplied the weight of the representative plant from each group by the number of plants in that group. We then calculated the sum of the weights of the three shrub groups. Finally, we averaged the fresh weight of both the herbs and shrubs in the three plots at the sampling site to obtain the field sampling dataset.

Because the estimation accuracy for the model was significantly affected by the quality of ground survey data, the ground survey data were strictly tested and standardized before the creation of the model. Based on the grassland type and average conditions over many years, certain data showing an abnormal performance were excluded from the dataset. Ultimately, a total of 1205 sites sampled for biomass data were selected, of which 975 aboveground sites were used to establish the model and the remaining 230 sites were employed for validating the accuracy of the model. As shown in Figure 1, the number of sampling sites was sufficiently large and their distribution was sufficiently even to accurately represent the ground biomass and obtain statistically significant biomass models. 


\subsection{Remote Sensing Data and its Processing}

\subsubsection{Introduction to MODIS Productivity Data}

The MODIS satellite sensor is one of the major sensors of the U.S. Earth Observation System (EOS). Generalized MODIS data cover 44 types of products. The MODIS data used in this study came from the MOD17A2 eight-day PSNnet (net photosynthesis) product, with a resolution of $1 \mathrm{~km}$, which is a global land vegetation net productivity product calculated by model [25] and has been validated and widely used in studies on productivity and biomass in different regions of the world [26-29].

The MOD17 product is a land productivity product calculated using the BIOME-BGC model and a light use efficiency model, in combination with remote sensing data. The essence of the core science in the MOD17 algorithm is the application of radiation conversion efficiency logic to predictions of daily GPP (Gross Primary Productivity) using satellite-derived FPAR (Fraction of Photosynthetically Active Radiation, from MOD15) and independent estimates of PAR (Absorption Ratio of Photosynthetically Active Radiation) and other surface meteorological fields (from the DAO). The subsequent estimates of maintenance and growth respiration terms are subtracted from GPP to arrive at NPP (Net Primary Productivity). The principles underlying daily PSNnet estimation are as follows:

$$
\varepsilon=\varepsilon_{\max } \times \text { TMIN_Scalar } \times \text { VPD_Scalar }
$$

where, $\varepsilon$ is the light use efficiency, $\varepsilon_{\max }$ is the maximum light use efficiency obtained from the Biome Parameter Look-Up Table (BPLUT) provided by NASA; TMIN_Scalar is the daily minimum temperature scalar, and VPD_Scalar is the daily average vapor pressure deficit scalar, which are used to calculate the scalars that attenuate $\varepsilon_{\max }$ to produce the final $\varepsilon$ used to predict GPP.

$$
\begin{gathered}
\mathrm{IPAR}=\mathrm{SWRad} \times 0.45 \\
\mathrm{APAR}=\mathrm{IPAR} \times \mathrm{FAR} \\
\mathrm{GPP}=\varepsilon \times \mathrm{APAR}
\end{gathered}
$$

where, SWRad is the incident shortwave radiation provided by the Data Assimilation Office (DAO) of NASA; IPAR is the photosynthetically active radiation incident on the vegetative surface; FAR is the absorption ratio of photosynthetically active radiation; and APAR is the photosynthetically active radiation absorbed by vegetation.

$$
\text { Leaf_Mass = LAI/SLA }
$$

where, LAI is the leaf area index obtained from the MOD15, and SLA is the projected leaf area for a given pixel obtained from the BPLUT.

$$
\text { Leaf_MR }=\text { Leaf_Mass } \times \text { leaf_mr_base } \times \text { Q10_mr }{ }^{[(\text {Tavg-20.0)/10.0] }}
$$

where, leaf_mr_base is the maintenance respiration of leaves obtained from the BPLUT and Tavg is the average daily temperature $\left({ }^{\circ} \mathrm{C}\right)$ estimated from the DAO meteorological data; Leaf MR is the leaf autotrophic respiration consumption.

$$
\begin{gathered}
\text { Froot_Mass }=\text { Leaf_Mass } \times \text { Froot_leaf_ratio } \\
\text { Froot_MR }=\text { Fine_Root_Mass } \times \text { froot_mr_base } \times \text { Q10_mr } r^{[(\text {Tavg-20.0)/10.0] }}
\end{gathered}
$$


where, Froot_leaf_ratio is the ratio of fine root to leaf mass obtained from the BPLUT; Froot_mr_base is the maintenance respiration per unit of fine roots at $20^{\circ} \mathrm{C}$ obtained from the BPLUT; and Froot_MR is the fine root autotrophic respiration consumption.

Finally, PSNnet $\left(\mathrm{kg} \cdot \mathrm{C} \cdot \mathrm{day}^{-1}\right)$ can be calculated from GPP using Equation (9):

$$
\text { PSNnet }=\text { GPP-Leaf_MR }- \text { Froot_MR }
$$

The process for the estimation of the MOD17A2 GPP (gross primary productivity) and PSNnet (net photosynthesis) products is illustrated in Figure 2.

Figure 2. Flowchart of the PSNnet estimation process.

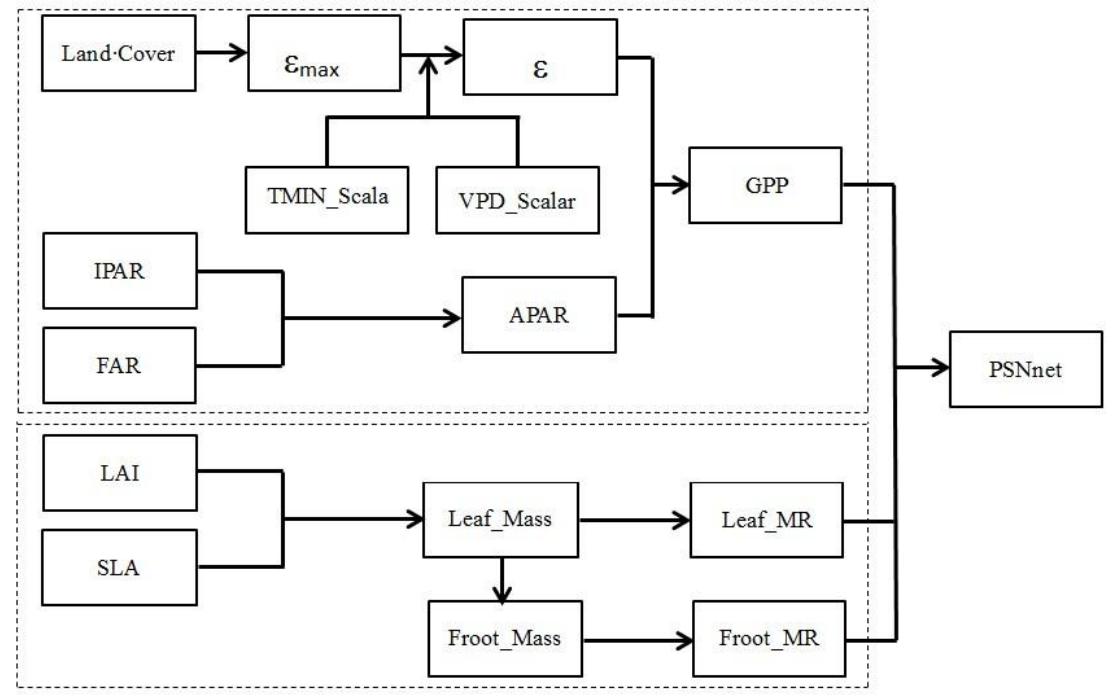

\subsubsection{Processing of Remote Sensing Data}

Prior to conducting biomass estimates using the MOD17A2 eight-day PSNnet data, preprocessing of the data was necessary. First, a mosaic image was obtained, and geometric projection transformation was performed. The administrative boundary vector data for the Xilingol grassland were then used to extract the data for the study area. In addition, there was noise in certain areas of the PSNnet data where pixels were filled with the invalid value 32,767. In this study, the noise mostly appeared in desert grasslands, which essentially have no vegetation cover. Therefore, to ensure the accuracy of the final estimates during processing, all these invalid values were set to 0 . Because there were many ground sampling sites selected for this study and they were evenly distributed, setting the values in a few areas to 0 does not have a significant effect on the statistical results. Further, to obtain a more accurate start time for the growing season and to ensure the accuracy of the accumulated productivity data, a statistical analysis of the productivity time series of the Xilingol grassland for the years 2005-2012 was conducted. The start time of PSNnet value every eight-day great than 0 was defined the start of growing season here, and the analytical results indicated a start time for the growing season of early to mid-March. Furthermore, the accumulation of PSNnet data every eight days from the beginning of the growing season to the peak of the growing season was obtained. Specifically, we can extract the mean PSNnet within a $1 \mathrm{~km}$ range for each sampling sites from the accumulated PSNnet data and establish a database of PSNnet and fresh grass weight data for the corresponding time. Then, based on the database, a statistical model was built for inversion of the aboveground biomass. 


\subsection{Establishment and Verification of the Model}

In this study, the field sampling data was wet weight and needed to be converted to air-dried weight. We converted the wet weights to air-dried weights using conversion coefficients for different grassland types employing "Chinese Grassland Resources" [30] as a reference, and we further converted the air-dried weights to dry weights with a $15 \%$ water content [31], as the indicator of the grassland aboveground biomass.

Based on the database, regression models between the aboveground biomass and the corresponding accumulated PSNnet value were established. These models primarily consisted of unitary linear, logarithm function, power function and exponential function models (Table 1). Using the reserved ground sampling data (approximately $20 \%$ of the total samples), we calculated the root-mean-square error (RMSE) and mean relative estimation error (REE) between the estimated values and the ground-measured values to evaluate the accuracy of the models [32]. The equations employed for error calculation were as follows:

$$
\begin{array}{r}
\text { RMSE }=\sqrt{\frac{\sum\left(\mathrm{Y}_{\mathrm{i}}-\mathrm{Y}_{\mathrm{i}}^{\prime}\right)^{2}}{\mathrm{~N}}} \\
\mathrm{REE}=\sqrt{\frac{\sum\left[\left(\mathrm{Y}_{\mathrm{i}}-\mathrm{Y}_{\mathrm{i}}^{\prime}\right) / \mathrm{Y}_{\mathrm{i}}^{\prime}\right]^{2}}{\mathrm{~N}}}
\end{array}
$$

where, $Y_{i}$ is the actual aboveground biomass (fresh weight), $Y_{i}^{\prime}$ is the aboveground biomass estimated by the model and $\mathrm{N}$ is the sample size.

\begin{tabular}{|c|c|c|c|c|c|c|}
\hline \multicolumn{2}{|c|}{ Model } & \multirow{2}{*}{$\begin{array}{c}\boldsymbol{R}^{2} \\
0.55\end{array}$} & \multirow{2}{*}{$\begin{array}{c}\text { F Value } \\
1168.75\end{array}$} & \multirow{2}{*}{$\begin{array}{c}\text { RMSE } \\
\left(\mathbf{g} \cdot \mathbf{m}^{-2}\right) \\
26.67\end{array}$} & \multirow{2}{*}{$\begin{array}{r}\text { REE } \\
0.31\end{array}$} & \multirow{2}{*}{$\begin{array}{c}\text { Precision } \\
(\%) \\
69\end{array}$} \\
\hline Unitary linear function & $y=1.097 x-4.776$ & & & & & \\
\hline Logarithm function & $y=71.308 \times \ln x-224.634$ & 0.55 & 1154.46 & 26.77 & 0.40 & 60 \\
\hline Power function & $y=0.361 x^{1.226}$ & 0.65 & 1739.58 & 27.43 & 0.39 & 61 \\
\hline Exponential function & $y=17.038 \times e^{0.0178 x}$ & 0.58 & 1315.50 & 34.52 & 0.43 & 57 \\
\hline
\end{tabular}

Table 1. Statistical models relating aboveground biomass to accumulated PSNnet.

Note: The numbers of regression and test samples were 975 and 230, respectively; $p<0.0001$; precision $=(1-\mathrm{REE}) \times 100 \%$; $\mathrm{x}$ is the accumulated PSNnet data $\left(\mathrm{C}_{-} \mathrm{g} \cdot \mathrm{m}^{-2}, \mathrm{C}\right.$ presents carbon $)$, $\mathrm{y}$ is the estimated aboveground biomass $\left(\mathrm{g} \cdot \mathrm{m}^{-2}\right)$.

The results indicate that the precision of the exponential function model was relatively low, whereas the precision of the unitary linear regression model was highest, at $69 \%$. The correlation between the grassland aboveground biomass estimated by the unitary linear model and the actual aboveground biomass was significant (Figure 3). Therefore, we selected the unitary linear regression model for estimating the aboveground biomass of the Xilingol grassland, and then analyzed the temporal and spatial characteristics of the aboveground biomass of the Xilingol grassland. 
Figure 3. Relationship between the estimated aboveground biomass and actual aboveground biomass.

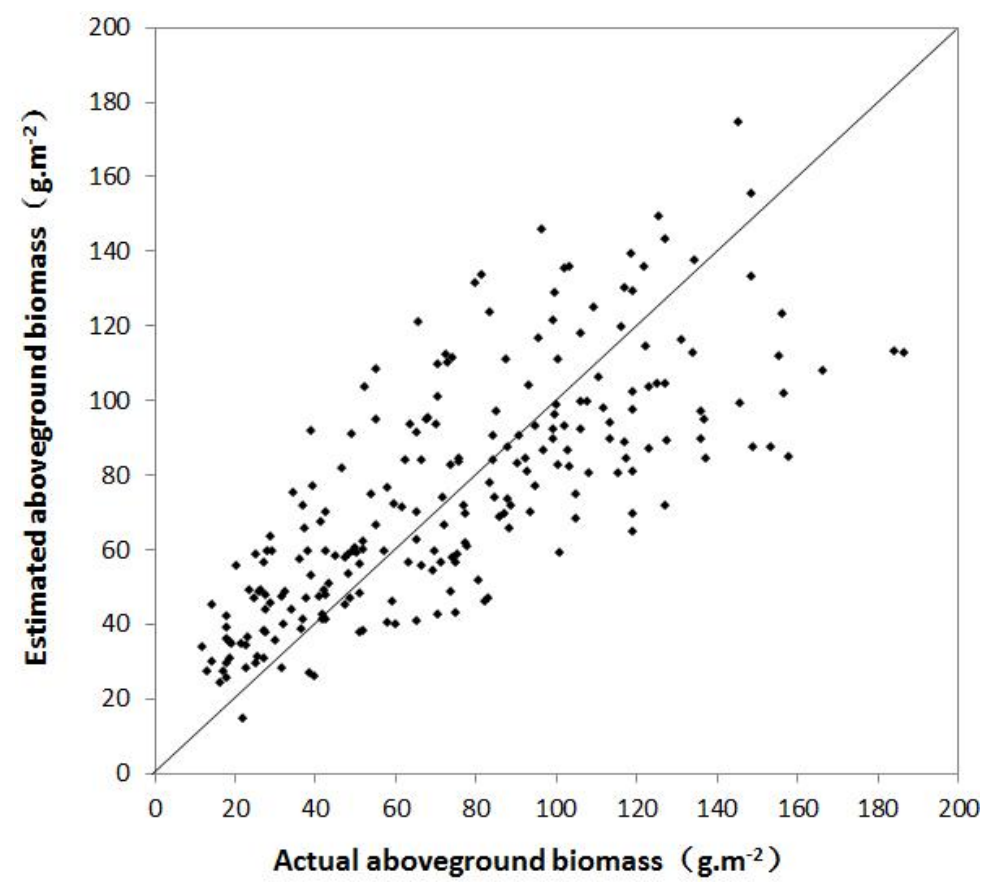

\section{Results}

\subsection{Total Aboveground Biomass and its Distribution in Different Banners}

The unitary linear regression model was selected for estimating the aboveground biomass of the Xilingol grassland for the years 2005-2012 (Table 2). The average aboveground biomass of the Xilingol grassland for the years 2005-2012 was $14.35 \mathrm{Tg}\left(1 \mathrm{Tg}=10^{12} \mathrm{~g}\right)$. The annual average aboveground biomass was highest in East Ujimqin Banner (approximately $4.15 \mathrm{Tg}$ ), $28.92 \%$ of the total biomass of the Xilingol grassland. The annual average aboveground biomass in West Ujimqin Banner was approximately $2.58 \mathrm{Tg}, 17.98 \%$ of the total biomass in the Xilingol grassland. As the biomass of these two Banners represented nearly one-half of the total biomass, the two banners play an important role in pasture management and in the protection of grassland resources in Xilingol. The annual average aboveground biomass in Erenhot City, Taibus Banner, Xianghuang Banner, Duolun County and Zhengxiangbai Banner were relatively low, accounting for less than $10 \%$ of the aboveground biomass of the Xilingol grassland.

An analysis of the data presented in Table 3 showed that the average density of the aboveground biomass of the Xilingol grassland for the years 2005-2012 was $71.32 \mathrm{~g} \cdot \mathrm{m}^{-2}$. This value is generally in agreement with the average aboveground biomass density estimated for the Xilingol grassland for the years 2001-2012 by Gao, et al. [23] using the NDVI. In addition, there was a substantial difference in the aboveground biomass density among the different banners. The aboveground biomass density was greater than $90 \mathrm{~g} \cdot \mathrm{m}^{-2}$ in Duolun County, Taipusi Banner, West Ujimqin Banner, Zhenglan Banner and East Ujimqin Banner, where growth conditions for grassland vegetation are generally good. In contrast, the aboveground biomass density in Erenhot City, Sonid Right Banner and Sonid Left Banner were relatively low, as growth conditions for grassland vegetation were generally poor in these areas. 
Table 2. Annual aboveground biomass in different banners.

\begin{tabular}{|c|c|c|c|c|c|c|c|c|c|c|}
\hline \multirow{2}{*}{ Banners } & \multirow{2}{*}{$\begin{array}{c}\text { Grassland } \\
\text { Area }\left(\mathbf{k m}^{2}\right)\end{array}$} & \multicolumn{9}{|c|}{ Total Aboveground Biomass ( $\mathrm{Tg}$ ) } \\
\hline & & 2005 & 2006 & 2007 & 2008 & 2009 & 2010 & 2011 & 2012 & Average \\
\hline East Ujimqin Banner & 45,060 & 5.72 & 3.79 & 2.49 & 3.90 & 4.06 & 4.15 & 4.11 & 5.00 & 4.15 \\
\hline Abaga Banner & 27,492 & 1.79 & 1.51 & 1.38 & 2.00 & 1.73 & 1.65 & 1.56 & 2.40 & 1.75 \\
\hline West Ujimqin Banner & 23,726 & 3.49 & 2.53 & 1.83 & 2.68 & 2.08 & 2.50 & 2.46 & 3.06 & 2.58 \\
\hline Sonid Left Banner & 34,814 & 1.21 & 1.00 & 1.01 & 1.30 & 1.20 & 0.95 & 1.05 & 1.54 & 1.15 \\
\hline Xilinhot City & 15,753 & 1.44 & 1.23 & 1.00 & 1.40 & 1.10 & 1.28 & 1.09 & 1.60 & 1.27 \\
\hline Erenhot City & 186 & 0.0029 & 0.0020 & 0.0017 & 0.0026 & 0.0020 & 0.0015 & 0.0017 & 0.0025 & 0.0021 \\
\hline Sonid Right Banner & 25,212 & 0.90 & 0.70 & 0.59 & 0.80 & 0.67 & 0.55 & 0.65 & 0.88 & 0.72 \\
\hline Zhenglan Banner & 10,281 & 1.09 & 1.05 & 0.84 & 1.15 & 0.99 & 0.87 & 1.05 & 1.15 & 1.02 \\
\hline Zhengxiangbai Banner & 6256 & 0.48 & 0.48 & 0.36 & 0.50 & 0.42 & 0.35 & 0.46 & 0.52 & 0.44 \\
\hline Xianghuang Banner & 5018 & 0.30 & 0.31 & 0.22 & 0.29 & 0.27 & 0.23 & 0.31 & 0.33 & 0.28 \\
\hline Duolun County & 3955 & 0.59 & 0.56 & 0.47 & 0.57 & 0.53 & 0.48 & 0.58 & 0.58 & 0.54 \\
\hline Taipusi Banner & 3496 & 0.43 & 0.47 & 0.36 & 0.50 & 0.39 & 0.38 & 0.46 & 0.48 & 0.43 \\
\hline Total & 201,249 & 17.44 & 13.62 & 10.56 & 15.07 & 13.42 & 13.39 & 13.79 & 17.54 & 14.35 \\
\hline
\end{tabular}

Table 3. Aboveground biomass in different banners.

\begin{tabular}{cccccccccccc}
\hline & Grassland & \multicolumn{7}{c}{ Aboveground Biomass Density $\left(\mathbf{g} \cdot \mathbf{m}^{-\mathbf{2}}\right)$} \\
\cline { 3 - 10 } Banners & Area $\left(\mathbf{k m}^{2}\right)$ & $\mathbf{2 0 0 5}$ & $\mathbf{2 0 0 6}$ & $\mathbf{2 0 0 7}$ & $\mathbf{2 0 0 8}$ & $\mathbf{2 0 0 9}$ & $\mathbf{2 0 1 0}$ & $\mathbf{2 0 1 1}$ & $\mathbf{2 0 1 2}$ & Average \\
\hline East Ujimqin Banner & 45,060 & 127.04 & 84.20 & 55.26 & 86.54 & 90.03 & 92.13 & 91.20 & 111.03 & 92.18 \\
Abaga Banner & 27,492 & 65.19 & 55.07 & 50.18 & 72.66 & 62.93 & 60.09 & 56.88 & 87.03 & 63.75 \\
West Ujimqin Banner & 23,726 & 147.30 & 106.82 & 77.13 & 112.89 & 87.87 & 105.18 & 103.72 & 129.01 & 108.74 \\
Sonid Left Banner & 34,814 & 34.62 & 27.98 & 29.09 & 37.37 & 34.37 & 27.31 & 30.24 & 44.28 & 33.16 \\
Xilinhot City & 15,753 & 91.60 & 78.25 & 63.23 & 88.41 & 69.78 & 81.17 & 69.25 & 101.70 & 80.42 \\
Erenhot City & 186 & 15.54 & 10.85 & 9.40 & 14.06 & 10.80 & 7.88 & 9.13 & 13.48 & 11.39 \\
Sonid Right Banner & 25,212 & 35.53 & 27.50 & 23.60 & 31.80 & 26.38 & 21.84 & 25.90 & 34.89 & 28.43 \\
Zhenglan Banner & 10,281 & 105.60 & 102.60 & 81.82 & 111.67 & 95.95 & 84.87 & 101.70 & 111.58 & 99.47 \\
Zhengxiangbai Banner & 6256 & 76.18 & 76.76 & 57.60 & 79.26 & 66.34 & 55.31 & 73.53 & 83.30 & 71.03 \\
Xianghuang Banner & 5018 & 59.94 & 61.44 & 44.64 & 57.57 & 52.96 & 45.02 & 62.25 & 65.43 & 56.16 \\
\hline
\end{tabular}


Table 3. Cont.

\begin{tabular}{|c|c|c|c|c|c|c|c|c|c|c|}
\hline \multirow{2}{*}{ Banners } & \multirow{2}{*}{$\begin{array}{l}\text { Grassland } \\
\text { Area }\left(\mathbf{k m}^{2}\right)\end{array}$} & \multicolumn{9}{|c|}{ Aboveground Biomass Density $\left(\mathrm{g} \cdot \mathrm{m}^{-2}\right)$} \\
\hline & & 2005 & 2006 & 2007 & 2008 & 2009 & 2010 & 2011 & 2012 & Average \\
\hline Duolun County & 3955 & 149.48 & 140.62 & 118.06 & 144.66 & 133.70 & 121.23 & 146.92 & 145.73 & 137.55 \\
\hline Taipusi Banner & 3496 & 122.19 & 135.71 & 103.88 & 141.70 & 110.21 & 108.85 & 131.52 & 138.07 & 124.02 \\
\hline Total & 201,249 & 86.66 & 67.67 & 52.48 & 74.90 & 66.66 & 66.51 & 68.53 & 87.15 & 71.32 \\
\hline
\end{tabular}

\subsection{Spatial Distribution of Aboveground Biomass}

There were significant spatial differences in the aboveground biomass of the Xilingol grassland (Figure 4). The overall trend of aboveground biomass was as follows: the eastern meadow grassland > the central typical grassland > the western desert grassland (Table 4). The average aboveground biomass density for the years 2005-2012 was highest in the eastern montane meadow $\left(156.07 \mathrm{~g} \cdot \mathrm{m}^{-2}\right)$ and temperate meadow steppe $\left(115.23 \mathrm{~g} \cdot \mathrm{m}^{-2}\right)$, followed by the low-land meadow $\left(86.31 \mathrm{~g} \cdot \mathrm{m}^{-2}\right)$ and the temperate steppe $\left(69.10 \mathrm{~g} \cdot \mathrm{m}^{-2}\right)$. Among these four grassland types, the area of the temperate steppe was largest, accounting for $55.19 \%$ of the total area of the Xilingol grassland and $54.19 \%$ of the total aboveground biomass in the study area. The aboveground biomass density in the temperate desert-steppe and the temperate steppe-desert was markedly lower than the overall average density $\left(70.36 \mathrm{~g} \cdot \mathrm{m}^{-2}\right)$. The western temperate desert contained almost no plants. Precipitation is the major factor influencing the differences in the spatial distribution of grassland aboveground biomass [33]. The annual precipitation in most areas of the Xilingol grassland was within a range of 200-300 mm, with an overall trend involving a gradual decrease from east to west. This trend was consistent with the spatial distribution pattern of the aboveground biomass [34].

Figure 4. Spatial distribution of the aboveground biomass of the Xilingol grassland $\left(\mathrm{g} \cdot \mathrm{m}^{-2}\right)$ from 2005-2012.

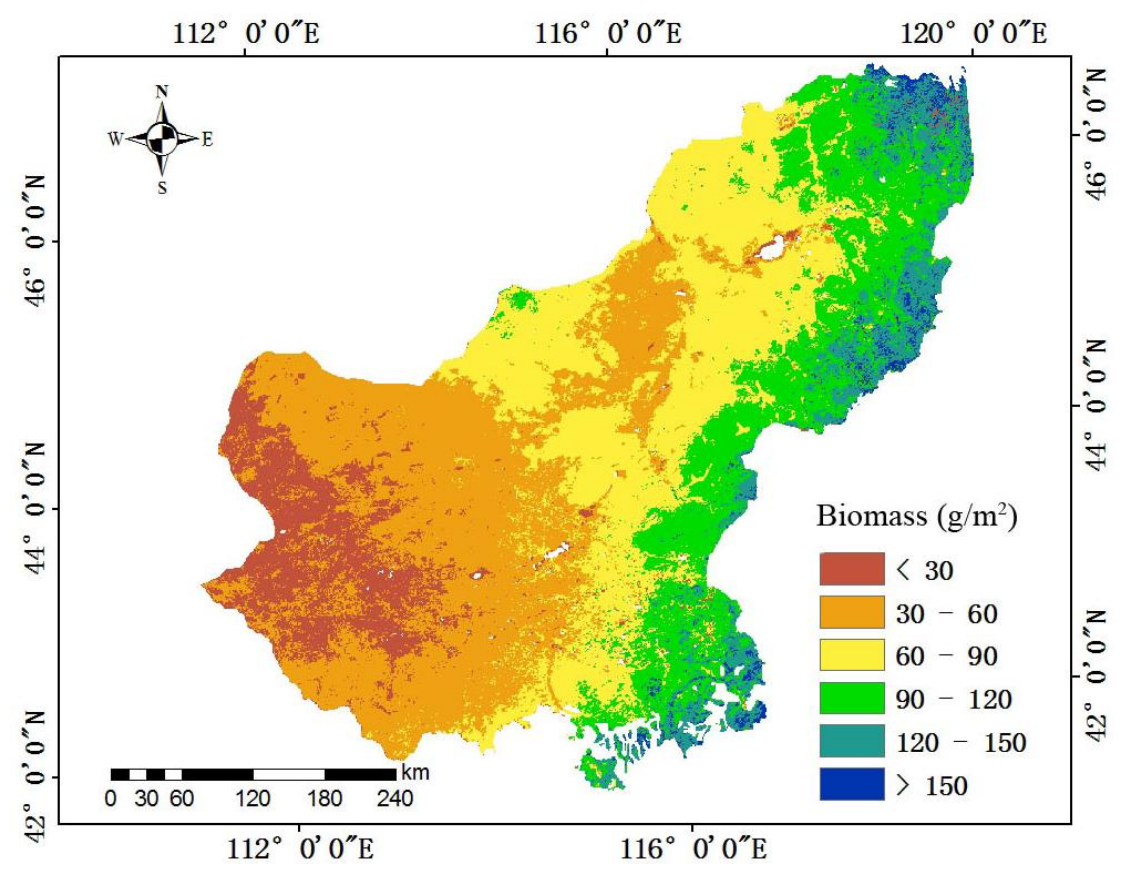


Table 4. Aboveground biomass density in the different grassland types.

\begin{tabular}{|c|c|c|c|c|c|c|c|c|c|c|}
\hline \multirow{2}{*}{ Grassland Types } & \multirow{2}{*}{$\begin{array}{l}\text { Grassland } \\
\text { Area }\left(\mathbf{k m}^{2}\right)\end{array}$} & \multicolumn{9}{|c|}{ Aboveground Biomass Density $\left(\mathrm{g} \cdot \mathrm{m}^{-2}\right)$} \\
\hline & & 2005 & 2006 & 2007 & 2008 & 2009 & 2010 & 2011 & 2012 & Average \\
\hline Low-land meadow & 25,981 & 109.74 & 83.87 & 62.04 & 88.41 & 79.65 & 80.92 & 84.84 & 101.02 & 86.31 \\
\hline Improved grassland & 472 & 67.42 & 63.52 & 50.80 & 68.73 & 58.06 & 54.71 & 60.26 & 73.89 & 62.17 \\
\hline Montane meadow & 1581 & 202.45 & 154.89 & 123.03 & 153.47 & 145.24 & 145.58 & 159.17 & 164.75 & 156.07 \\
\hline Temperate meadow-steppe & 24,875 & 155.81 & 110.19 & 75.29 & 109.83 & 110.44 & 111.83 & 117.66 & 130.82 & 115.23 \\
\hline Temperate steppe-desert & 5108 & 24.94 & 19.78 & 19.66 & 24.91 & 23.72 & 17.07 & 20.33 & 28.69 & 22.39 \\
\hline Temperate steppe & 108,488 & 80.40 & 65.11 & 51.62 & 75.06 & 63.34 & 64.82 & 64.39 & 88.02 & 69.10 \\
\hline Temperate desert-steppe & 29,598 & 30.68 & 23.36 & 23.89 & 31.03 & 27.79 & 21.17 & 24.20 & 35.71 & 27.23 \\
\hline Temperate desert & 143 & 22.93 & 16.58 & 16.91 & 22.43 & 18.53 & 14.64 & 16.94 & 23.93 & 19.11 \\
\hline Marsh & 330 & 126.45 & 71.32 & 55.81 & 83.17 & 75.64 & 84.50 & 84.36 & 97.95 & 84.90 \\
\hline Total & 196,576 & 85.88 & 66.52 & 51.54 & 73.88 & 65.71 & 65.71 & 67.39 & 86.29 & 70.36 \\
\hline
\end{tabular}

\subsection{Interannual Variation in Aboveground Biomass}

There were obvious fluctuations in the aboveground biomass of the Xilingol grassland between the years 2005 and 2012. These biomass values ranged from 10.56-17.54 Tg. As shown in Figure 5, the lowest biomass occurred in 2007 , at $10.56 \mathrm{Tg}$, approximately $26 \%$ lower than the mean annual average biomass. The highest biomass was $17.54 \mathrm{Tg}$, in 2012. There were large interannual fluctuations in the aboveground biomass of the Xilingol grassland from 2005-2009, with an initial decrease being observed prior to an increasing trend. The grassland aboveground biomass from 2009-2012 exhibited an increasing trend, with biomass peaking in 2012.

Figure 5. Variation in the aboveground biomass of the Xilingol grassland from 2005-2012.

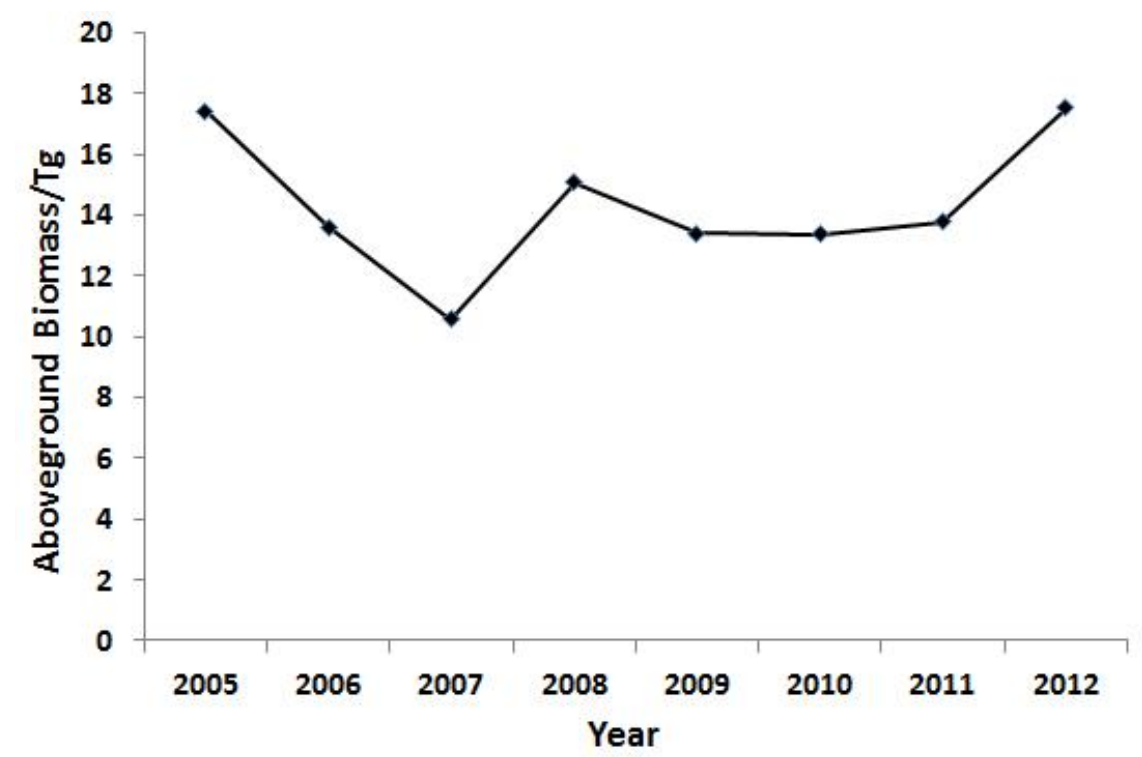


The aboveground biomass of different grassland types appeared to fluctuate from 2005-2012 (Figure 6). Large variations occurred in the temperate meadow-steppe and the typical grassland, which presented higher yields; whereas there was little change in the temperate desert-steppe and temperate steppe-desert, which showed lower yields. From 2005-2012, the overall grassland production in the montane meadow and the temperate meadow-steppe decreased, whereas it remained steady after showing fluctuations in the lowland and the temperate meadow and showed little change in the temperate desert-steppe and the temperate steppe-desert.

Figure 6. Interannual variations in the aboveground biomass in different grassland types.

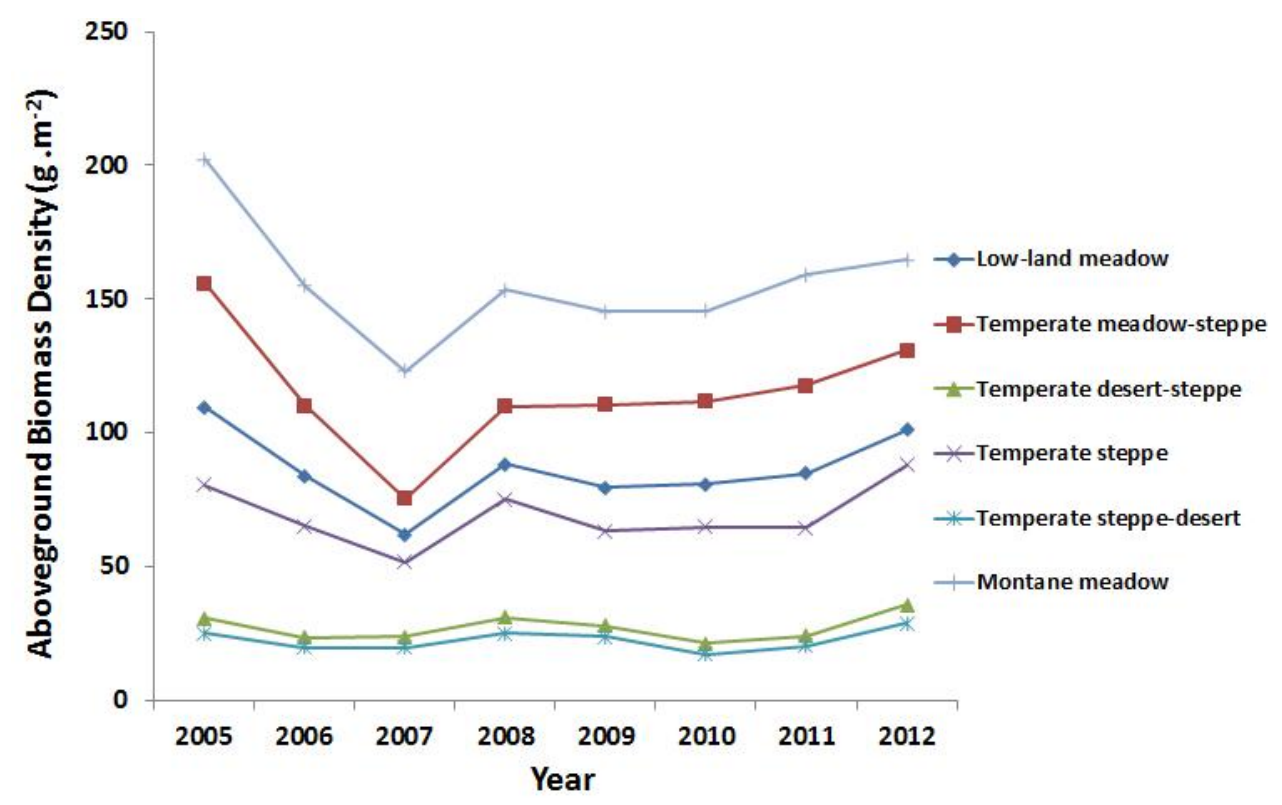

\section{Discussions}

\subsection{Potentials Analysis of Model}

A significant empirical relationship was found between the accumulated PSNnet data and the aboveground biomass data, showing good prospects for the application of MODIS productivity data in combination with ground sampling data to establish models for biomass inversion. There are three reasons to support this conclusion, as follows:

(1) Through the accumulation of PSNnet data every eight days from the beginning of the growing season to the peak of the growing season, a good correlation was achieved between the obtained accumulated PSNnet data and the peak growing season NDVI data for the corresponding spatial point, showing coefficients of determination $\left(R^{2}\right)$ up to 0.75 (Figure 7). Because there have been many previous studies on statistical models of the NDVI and aboveground biomass [35-38], we can assume a good correlation between the PSNnet data and the aboveground biomass data. Furthermore, we can assume that using the PSNnet data and the aboveground biomass data to build the model and then retrieve the aboveground biomass data is a practical method. In addition, the MODIS productivity data used in this study fully considered the effects of temperature, precipitation and other climatic factors during the process of estimating vegetation productivity. Compared with the NDVI data employed in 
traditional methods of biomass estimation, MODIS productivity data can better reflect the effects of environmental stresses.

Figure 7. Relationship between the accumulated PSNnet data and NDVI data.

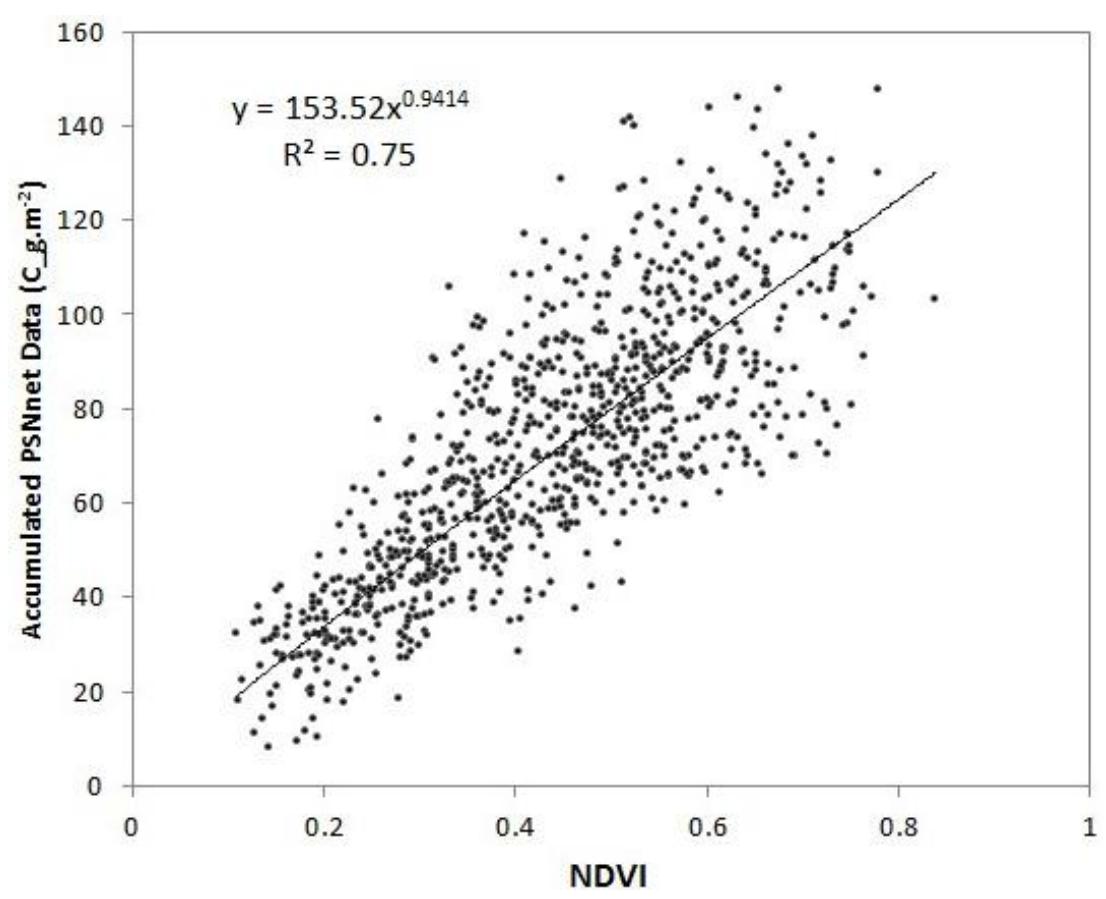

Note: $x$ is NDVI, $y$ is the accumulated PSNnet data $\left(C \_g \cdot \mathrm{m}^{-2}\right)$.

(2) The temporal matching between remotely sensed images and ground survey greatly affects the accuracy of remote sensing based models for grassland biomass estimation. The database of the extensive filed samples and their matching remotely sensed data is the basis of improving the model precision and stability. In this study, a sound database combining multi-year accumulated PSNnet data and ground survey biomass data with strict temporal matching was developed, which was further applied to biomass estimation models.

(3) Two methods are often used to evaluate model performances. One is based on the coefficient of determination $\left(R^{2}\right)$, another way is to assess model error. In general, a high $R^{2}$ or a low error value often indicates a good fit between the model developed and the ground survey data [39]. In this study, we compared the correlation between NDVI data and biomass, as well as accumulated PSNnet data and biomass. The result showed that $R^{2}$ between calculated PSNnet data and biomass was a little higher than $R^{2}$ between NDVI data and biomass, as shown in Figure 8 . We used ground survey data from the Xilingol grassland for the years 2005-2012 and MODIS productivity data for the same time period to establish statistics-based models for biomass estimation, with an overall accuracy of $69 \%$, which is close to highest accuracy (74\%) by Jin, et al. [38]. In addition, NDVI data are prone to an "oversaturation" phenomenon if the vegetation coverage is higher, which decreases the sensitivity of biomass estimation, whereas MODIS productivity data can overcome this oversaturation problem. Therefore, in high vegetation cover conditions, the biomass estimation accuracy by MODIS productivity data would be higher than the biomass estimation accuracy by NDVI data. 
Figure 8. $R^{2}$ between remotely sensed data and ground survey data.
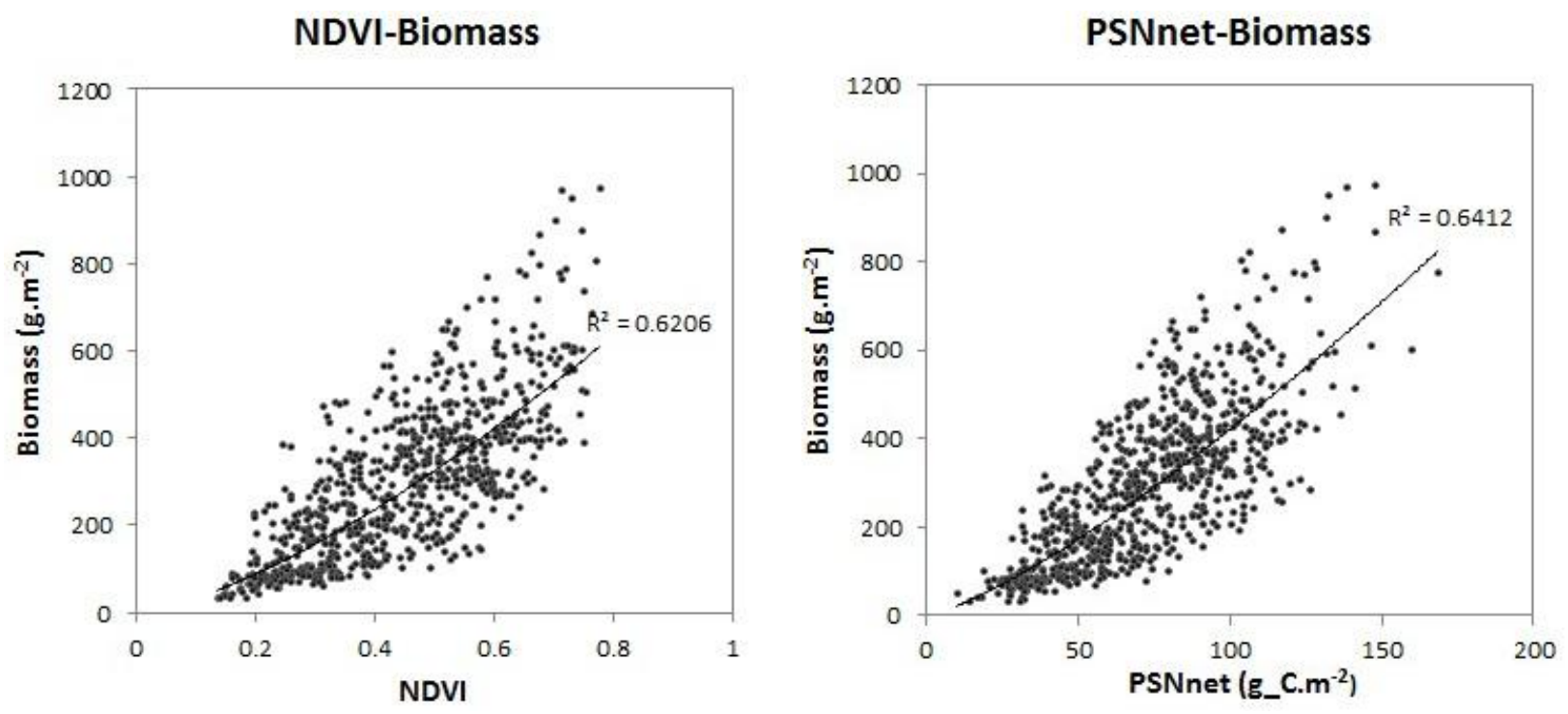

\subsection{Uncertainties of Model}

In this study, based on ground survey data from the Xilingol grassland for the years 2005-2012 and MODIS productivity data for the same time period, we developed statistical models based on the relationship between the PSNnet data and aboveground biomass data and then selected the optimal model to estimate the grassland aboveground biomass of the Xilingol grassland. However, our estimate still retains some uncertainties for the following reasons. First, there exists the scale effect between remotely sensed data and ground survey data. The spatial resolution of MODIS productivity data is $1 \mathrm{~km}$, differing from the size of quadrat. In the course of the sampling, we have taken the average value of multiple samples to reduce the estimation error caused by the scale effect. Second, the remotely sensed data used in this study came from the MOD17A2 eight-day PSNnet product, which is a global land vegetation net productivity product calculated by model and has been validated widely, across most of the world. In the process of performing these calculations, nevertheless, since some of the maintenance respiration costs and all of the growth respiration costs have not been accounted for in the daily timestep, the daily output from this algorithm is termed PSNnet (net photosynthesis), to differentiate it from the true daily NPP. This reason has magnified the contrast between net photosynthesis and actual biomass, and becomes the important uncertainty source for biomass estimation. In addition, although the MODIS-PSNnet dataset has been processed with a series of corrections, there is still a certain level of deviation, which causes uncertainty in the estimation. Understanding and identifying the sources of uncertainties and then devoting efforts to improving them are critical in improving grassland aboveground biomass estimation performance; therefore, more research is needed in the future for reducing the uncertainties from different sources in the aboveground biomass estimation procedure.

\subsection{Comparison with Previous Estimates}

As shown in Table 4, the average aboveground biomass densities were estimated to be $27.23 \mathrm{~g} \cdot \mathrm{m}^{-2}$ for the temperate desert steppe, $69.10 \mathrm{~g} \cdot \mathrm{m}^{-2}$ for the temperate steppe and $115.23 \mathrm{~g} \cdot \mathrm{m}^{-2}$ for the temperate 
meadow steppe. A comparison of our estimates with these previous values (Table 5 [40-43]) showed that our estimate was significantly lower than the previous estimates, and the reasons for this difference could be related to the following three aspects. First, the influence on ground survey data from different times and regions is the major reason for this difference. For example, we used field sampling data from multi-year field survey data collected by our research group and a large-scale field campaign organized by the GMSC between 2006 and 2012, whereas Ma, et al. [41] gathered 113 field samples from 2002-2005, Piao, et al. [42] used national grassland resource inventory data between 1982 and 1999. Previous studies have mainly focused on large scales, including all types of grasslands in China or Inner Mongolia, whereas this study only concerns grasslands in Xilingol. Second, the sampling method employed in these studies may have contributed to this difference. Although biomass harvest is a commonly used method of grassland quadrat survey, there are differences in actual practical operations. Different standards of sampling, including sample locations (enclosed or not) and collected objects (including standing dead biomass and litter biomass or not), dramatically influence sampling. The third aspect is the approach taken in the estimation process. For example, Ma, et al. [41] calculated the biomass densities for different grassland types based on field samples and further estimated the biomass according to different grassland types. Compared with this method, the method based on remote sensing can represent the spatial details of the aboveground biomass across the entire study area, thereby expanding the study area and reducing the uncertainty of the estimates.

Table 5. Aboveground biomass densities from different studies.

\begin{tabular}{ccccc}
\hline & & \multicolumn{3}{c}{ Aboveground Biomass Densities $\left(\mathbf{g}^{\left.-\mathbf{m}^{-2}\right)}\right.$} \\
\cline { 3 - 5 } Researchers & Study Area & $\begin{array}{c}\text { Temperate Desert } \\
\text { Steppe }\end{array}$ & $\begin{array}{c}\text { Temperate } \\
\text { Steppe }\end{array}$ & $\begin{array}{c}\text { Temperate Meadow } \\
\text { Steppe }\end{array}$ \\
\hline Ni, et al. $[40]$ & China & 45.56 & 88.96 & 146.47 \\
Ma, et al. $[41]$ & Inner Mongolia & 56.5 & 133.4 & 196.7 \\
Piao, et al. $[42]$ & China & 43.57 & 91.52 & 144.9 \\
Fan, et al. $[43]$ & China & 111.11 & 151.11 & 182.22 \\
\hline
\end{tabular}

In addition to the studies cited above, several studies have obtained results similar to our results. Jin, et al. [38] estimated the average aboveground biomass density of the temperate desert steppe, the temperate steppe and the temperate meadow steppe in in the Xilingol grassland to be 23.1, 55.7 and $98.6 \mathrm{~g} \cdot \mathrm{m}^{-2}$, respectively. Gao, et al. [23] used field-based biomass samples and MODIS time series data sets to establish two empirical models based on the relationship of the normalized difference vegetation index (NDVI) to aboveground biomass in the Xilingol grasslands of northern China. The results showed that the average aboveground biomass densities for temperate desert-steppe, temperate steppe and temperate meadow-steppe were $21.2,59.6$ and $111.3 \mathrm{~g} \cdot \mathrm{m}^{-2}$, respectively. The field biomass measurements obtained at the same time and from the same regions contributed to the consistency of these results. However, several differences remained among studies as a result of the use of different remotely sensed data as input parameter and different regression models. The MODIS productivity data is a global land vegetation net productivity product calculated by model, differing from the vegetation 
index data. Using a remote sensing vegetation index to estimate aboveground biomass provides accurate and rapid results, but the limitations of the vegetation index itself may affect the obtained grassland biomass estimates. Compared with NDVI data, MODIS productivity data can overcome the problem of high error rates in low-coverage grasslands and the oversaturation problem in high-coverage grasslands. In addition, MODIS productivity data can better reflect the effects of environmental stresses. However, the method using MODIS productivity data for biomass estimation should be improved to achieve more accurate estimates of grassland biomass in the future.

\section{Conclusions}

This study took the Xilingol grassland as a case study and used ground survey data and MODIS productivity data for the growing seasons of the years 2005-2012 to build a unitary linear regression model to retrieve the aboveground biomass of the Xilingol grassland, and then analyze the spatial and temporal distribution of aboveground biomass. The grassland aboveground biomass averaged 14.35 Tg in the Xilingol grassland during the years 2005-2012, and showed a gradually decreasing trend from east to the west. There were large interannual variations in the aboveground biomass, ranging from 10.56-17.54 Tg, and the aboveground biomass showed differences among different grassland types.

The study made up for the inadequacy of vegetation index to estimate the grassland biomass, and provided an improvement for grassland biomass estimation. Although the study showed promising results for remote sensing based grassland biomass estimation, there are limitations to the accuracy of biomass inversion using MODIS productivity data, therefore, further work is needed to improve the estimation accuracy. In addition, spatio-temporal patterns of aboveground biomass and their relationships with climate factors still need further research in the Xilingol grassland. Gao, et al. [23] have already studied the relationship between GSP (growing season total precipitation) with grassland biomass and the relationship between GST (growing season average temperature) with grassland biomass. However, the climate factors are much more than these. For example, how the growing season maximum and minimum temperatures affect grassland biomass and whether the temperature in winter affects grassland biomass need in-depth research. Therefore, the grassland response to climate change is complex, and deserves more detailed and deeper inquiry in future research.

\section{Acknowledgments}

We are grateful for support from the National Natural Science Foundation of China (NSFC, 31372354), International Science \& Technology Cooperation Program of China (2013DFR30760), Grassland Monitoring and Supervision Center Ministry of Agriculture, China (415-1), and the Agricultural Scientific Research Fund of Outstanding Talents and the Open Fund for the Key Laboratory of Agri-informatics, Ministry of Agriculture, China (2013010) . We thank Grassland Monitoring and Supervision Center Ministry of Agriculture, China for providing the ground truth data.

\section{Author Contributions}

All authors contributed extensively to the work. Fen Zhao, Bin $\mathrm{Xu}$ designed and performed experiments. Bin $\mathrm{Xu}$ and Yunxiang Jin reviewed the manuscript and gave comments and suggestions to 
the manuscript. Lang Xia performed the satellite datasets preprocessing. All authors performed the field survey. All authors participated in editing and revision of the paper.

\section{Conflicts of Interest}

The authors declare no conflict of interest.

\section{References}

1. Li, J.Y.; Yang, X.C.; Jin, Y.X.; Yang, Z.; Huang, W.G.; Zhao, L.N.; Gao, T.; Yu, H.D.; Ma, H.L.; Qin, Z.H.; et al. Monitoring and analysis of grassland desertification dynamics using Landsat images in Ningxia, China. Remote Sens. Environ. 2003, 138, 19-26.

2. Xu, B.; Yang, X.C. Calculation of grass production and balance of livestock carrying capacity in rangeland region of Northeast China. Geogr. Res. 2009, 28, 402-408.

3. Fang, J.Y.; Ke, J.H.; Tang, Z.R.; Chen, A.P. Implications and estimations of four terrestrial productivity parameters. Acta Phytoecol. Sin. 2001, 25, 414-419.

4. Li, Z.Q.; Liu, Z.G.; Chen, Z.Z.; Yang, Z.G. The effects of climate changes on the productivity in the Inner Mongolia steppe of China. Acta Pratacult. Sin. 2003, 12, 4-10.

5. Gao, H.; Pan, X.B.; Fu, Y. Influence of climate change on potential climate productivity in grassland of Central Inner Mongolia. Chin. J. Agrometeorol. 2009, 30, 277-282.

6. Yang, Z.L.; Du, W.X.; Hou, Q.; Li, X.C.; Wang, B.C. Regional analysis of climate change in the east of Inner Mongolia and its potential productivity of grassland. Chin. J. Grassl. 2008, 30, 62-66.

7. Liu, A.J.; Wang, J.J.; Han, J.G. Study on method of estimating net primary production of rangeland by remote sensing-A case study of Xilingol grassland. Chin. J. Grassl. 2007, 29, 31-38.

8. Parton, W.J.; Scurlock, J.M.O.; Ojima, D.S.; Gilmanov, T.G.; Scholes, R.J.; Schimel, D.S.; Kirchner, T.; Menaut, J.-C.; Seastedt, T.; Garcia Moya, E.; et al. Observations and modeling of biomass and soil origaniac matter dynamics for the grassland Biome Worldwide. Glob. Biogeoch. Cycles 1993, 7, 785-809.

9. Luo, G.P.; Han, Q.F.; Zhou, D.C.; Li, L.; Chen, X.; Li, Y.; Hu, Y.K.; Li, B.L. Moderate grazing can promote aboveground primary production of grassland under water stress. Ecol. Complex. 2012, $11,126-136$.

10. Goetz, S.J.; Prince, S.D.; Goward, S.N.; Thawley, M.M.; Small, J. Satellite remote sensing of primary production: An improved production efficiency modeling approach. Ecol. Model. 1999, 122, 239-255.

11. Feng, X.M.; Zhao, Y.S. Grazing intensity monitoring in Northern China steppe: Integrating CENTURY model and MODIS data. Ecol. Indic. 2011, 11, 175-182.

12. Zhang, F.; Zhou, G.S.; Wang, Y.H. Dynamics simulation of Net Primary Productivity by a satellite data-driven CASA model in Inner Mongolian typical steppe, China. J. Plant Ecol. 2008, 32, 786-797.

13. Li, G.; Xin, X.P.; Wang, D.L.; Shi, R.X. Application of improved CASA model in productivity evaluation of grassland in Inner Mongolia. Chin. J. Ecol. 2007, 26, 2100-2106. 
14. Liu, Y.; Zhao, Y.S.; Feng, X.M.; Liu, Z.H. Research on a remote sensing-based net primary productivity model for semi-arid grassland. J. Grad School Chin. Acad. Sci. 2006, 23, 620-627.

15. Ruimy, A.; Dedieu, G.; Saugier, B. TURC: A diagnostic model of continental gross primary productivity and net primary productivity. Glob. Biogeochem. Cycles 1996, 10, 269-285.

16. Seaquist, J.W.; Olsson, L.; Ardo, J. A remote sensing-based primary production model for grassland biomes. Ecol. Model. 2003, 169, 131-155.

17. Li, Z.L.; Wu, H.; Wang, N.; Qiu, S.; Sobrino, J.A.; Wan, Z.M.; Tang, B.H.; Yan, G.J. Land surface emissivity retrieval from satellite data. Int. J. Remote Sens. 2013, 34, 3084-3127.

18. Li, Z.L.; Tang, R.L.; Wan, Z.M.; Bi, Y.Y.; Zhou, C.H.; Tang, B.H.; Yan, G.J.; Zhang, X.Y. A review of current methodologies for regional evapotranspiration estimation from remotely sensed data. Sensors 2009, 9, 3801-3853.

19. Zheng, L.Y.; Zhang, J.H. Research advances in the evaluation and estimation of grassland Net Primary Production. Trans CSAE 2007, 23, 279-285.

20. Piao, S.L.; Fang, J.Y.; He, J.S.; Xiao, Y. Spatial distribution of grassland biomass in China. Acta Phytoecol. Sin. 2004, 28, 491-498.

21. Xu, B.; Yang, X.C.; Tao, W.G.; Qin, Z.H.; Liu, H.Q.; Miao, J.M. Remote sensing monitoring upon the grass production in China. Acta Ecol. Sin. 2007, 27, 405-413.

22. Yang, Y.H.; Fang, J.Y.; Pan, Y.D.; Ji, C.J. Aboveground biomass in Tibetan grasslands. J. Arid. Environ. 2009, 73, 91-95.

23. Gao, T.; Yang, X.C.; Jin, Y.X.; Ma, H.L.; Li, J.Y.; Yu, H.D.; Yu, Q.Y.; Xiao, Z.; Xu, B. Spatio-temporal variation in vegetation biomass and its relationships with climate factors in the Xilingol grasslands, Northern China. PLoS One. 2013, 8, doi:10.1371/journal.pone.0083824.

24. Department of Animal Husbandry and Veterinary. The Basic Characteristics of Chinese Grassland Types. In Rangeland Resources of China, 1st ed.; China Science and Technology Press: Beijing, China, 1996; pp. 175-208. (In Chinese)

25. Zhao, M.S.; Heinsch, F.A.; Nemani, R.R.; Running, S.W. Improvements of the MODIS terrestrial gross and net primary production global data set. Remote Sens. Environ. 2005, 95, 164-176.

26. Turner, D.P.; Ritts, W.D.; Cohen, W.B.; Gower, S.T.; Running, S.T.; Zhao, M.S.; Costa, M.H.; Kirschbaum, A.A.; Ham, J.M.; Saleska, S.R.; et al. Evaluation of MODIS NPP and GPP products across multiple biomes. Remote Sens. Environ. 2006, 102, 282-292.

27. Fensholt, R.; Sandholt, I.; Rasmussen, M.S.; Simon, S.; Diouf, A. Evaluation of satellite based primary production modelling in the semi-arid Sahel. Remote Sens. Environ. 2006, 105, 173-188.

28. Guo, X.Y.; He, Y.; Shen, Y.P.; Feng, D. Analysis of the Terrestrial NPP based on the MODIS in the source regions of Yangtze and Yellow Rivers from 2000 to 2004. J. Glaciol. Geocryol. 2006, 28, $512-518$.

29. Wang, L.J.; Niu, Z.; Kuang, D. An analysis of the Terrestrial NPP from 2002 to 2006 in China based on MODIS data. Remote Sens. Land Res. 2010, 4, 113-116.

30. Department of Animal Husbandry and Veterinary. The Yield Evaluation of Chinese Grassland. In Rangeland Resources of China, 1st ed.; China Science and Technology Press: Beijing, China, 1996; pp. 353-358. (In Chinese) 
31. Fang, J.Y.; Liu, G.H.; Xu, S.L. Carbon Pools in Terrestrial Ecosystems in China. In Emissions and Their Relevant Processes of Greenhouse Gases in China, 1st ed.; Wang, G.C., Wen, Y.P., Eds.; China Environment Science Press: Beijing, China, 1996; pp. 109-128. (In Chinese)

32. Gao, T.; Xu B.; Yang, X.C.; Jin, Y.X.; Ma, H.L.; Li, J.Y.; Yu, H.D. Estimation of aboveground biomass by remote sensing in the Western Inner Mongolia grassland. J. Des. Res. 2013, 2, 597-603.

33. Wu, Z.T.; Dijkstra, P.; Koch, G.W.; Penuelas, J.; Hungate, B.A. Responses of terrestrial ecosystems to temperature and precipitation change: A meta-analysis of experimental manipulation. Glob. Chang. Biol. 2011, 17, 927-942.

34. Jin, Y.X.; Xu, B.; Yang, X.C.; Li, J.Y.; Wang, D.L.; Ma, H.L. Remote sensing dynamic estimation of grass production in Xilingol, Inner Mongolia. Sci. Sin. Vitae 2011, 41, 1185-1195.

35. Gao, T.; Xu, B.; Yang, X.C.; Jin, Y.X.; Ma, H.L.; Li, J.Y.; Yu, H.D. Using MODIS time series data to estimate aboveground biomass and its spatio-temporal variation in Inner Mongolia's grassland between 2001 and 2011. Int. J. Remote Sens. 2013, 34, 7796-7810.

36. Casady, G.; van Leeuwen, W.; Reed, B. Estimating winter annual biomass in the Sonoran and Mojave deserts with satellite- and ground-based observations. Remote Sens. 2013, 5, 909-926.

37. Lu, D.S. Aboveground biomass estimation using Landsat TM data in the Brazilian Amazon. Int. J. Remote Sens. 2005, 26, 2509-2525.

38. Jin, Y.X.; Yang, X.C.; Qiu, J.J.; Li, J.Y.; Gao, T.; Wu, Q.; Zhao, F.; Ma, H.L.; Yu, H.D.; Xu, B. Remote sensing-based biomass estimation and its spatio-temporal variations in temperate grassland, Northern China. Remote Sens. 2014, 6, 1496-1513.

39. Lu, D.S. The potential and challenge of remote sensing-based biomass estimation. Int. J. Remote Sens. 2006, 27, 1297-1328.

40. Ni, J. Estimating net primary productivity of grasslands from field biomass measurements in temperate northern China. Plant Ecol. 2004, 174, 217-234.

41. Ma, W.H.; Yang, Y.H.; He, J.S.; Zeng, H.; Fang, J.Y. Biomass and its relationship with environmental factors of temperate grassland in Inner Mongolia. Sci. Sin. Vitae 2008, 38, 84-92.

42. Piao, S.L.; Fang, J.Y.; Zhou, L.M.; Tan, K.; Tao, S. Changes in biomass carbon stocks in China's grasslands between 1982 and 1999. Glob. Biogeochem. Cycles 2007, 21, doi:10.1029/2005GB002634.

43. Fan, J.W.; Zhong, H.P.; Harris, W.; Yu, G.R.; Wang, S.Q.; Hu, Z.M.; Yue, Y.Z. Carbon storage in the grasslands of China based on field measurements of above- and below-ground biomass. Clim. Chang. 2008, 86, 375-396.

(C) 2014 by the authors; licensee MDPI, Basel, Switzerland. This article is an open access article distributed under the terms and conditions of the Creative Commons Attribution license (http://creativecommons.org/licenses/by/3.0/). 